
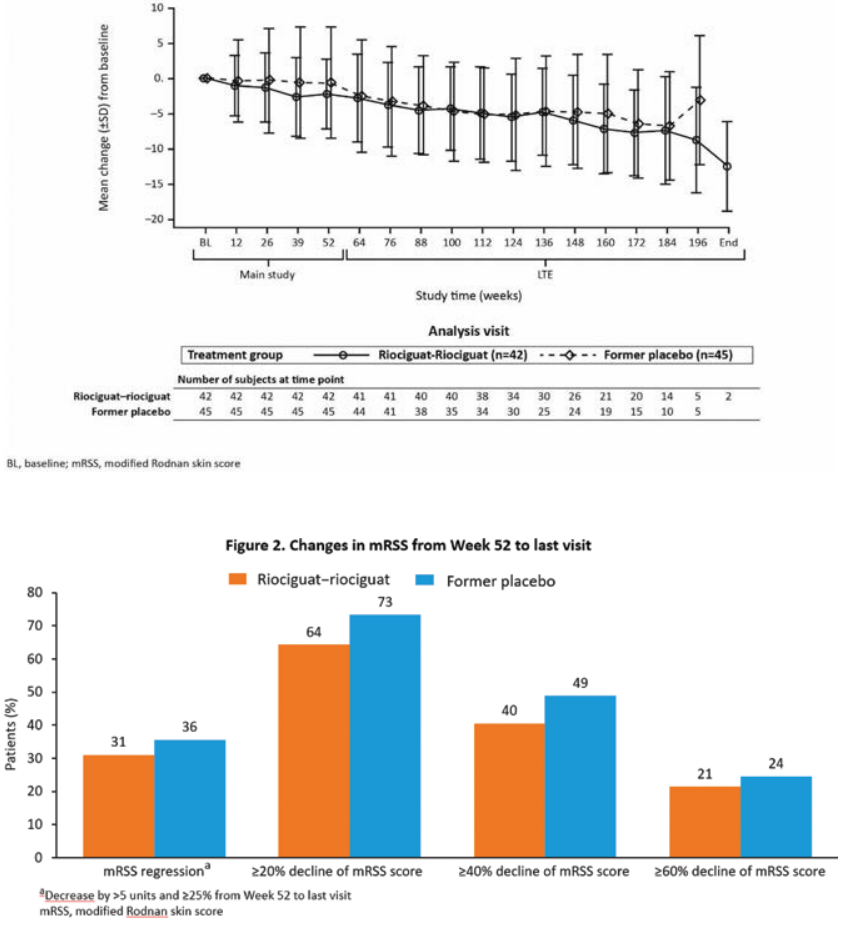

Acknowledgments: RISE-SSc was jointly funded by Bayer AG and Merck Sharp \& Dohme Corp., a subsidiary of Merck \& Co., Inc., Kenilworth, NJ, USA. Disclosure of Interests: Dinesh Khanna Shareholder of: Eicos, Grant/research support from: NIH NIAID, NIH NIAMS, Consultant of: Acceleron, Actelion, Bayer, BMS, Boehringer-Ingelheim, Corbus, Galapagos, Genentech/Roche, GSK, Mitsubishi Tanabi, Sanofi-Aventis/Genzyme, UCB Pharma, Janet Pope Grant/ research support from: AbbVie, Bristol-Myers Squibb, Eli Lilly \& Company, Merck, Roche, Seattle Genetics, UCB, Consultant of: AbbVie, Actelion, Amgen, Bayer, Boehringer Ingelheim, Bristol-Myers Squibb, Eicos Sciences, Eli Lilly \& Company, Emerald, Gilead Sciences, Inc., Janssen, Merck, Novartis, Pfizer, Roche, Sandoz, Sanofi, UCB, Speakers bureau: UCB, Marco Matucci-Cerinic Grant/ research support from: Actelion, MSD, Bristol-Myers Squibb, Speakers bureau: Acetelion, Lilly, Boehringer Ingelheim, Masataka Kuwana Grant/research support from: Acetelion, Consultant of: Acetelion, Bayer, Chugai, Corbus Pharmaceuticals, CSL Behring and Reata Pharmaceuticals. He was a member of the SENSCIS trial Steering Committee (Boehringer Ingelheim), Christopher Denton Grant/research support from: GlaxoSmithKline, CSL Behring, and Inventiva, Consultant of: Medscape, Roche-Genentech, Actelion, GlaxoSmithKline, Sanofi Aventis, Inventiva, CSL Behring, Boehringer Ingelheim, Corbus Pharmaceuticals, Acceleron, Curzion and Bayer, Yannick Allanore Grant/research support from: BMS, Inventiva, Roche, Sanofi, Consultant of: Actelion, Bayer AG, BMS, BI, Melanie Wosnitza Employee of: Bayer AG, Marie-Elise Truchetet: None declared, Gabriella Szücs: None declared, Wendy Stevens: None declared, Viginia Steen Grant/research support from: The associated affiliation has received grants/ research from Boehringer Ingelheim, Corbus Pharmaceuticals, CSL Behring, Eicos, Galapagos, Immune Tolerance Network, Reata, Consultant of: Virginia Steen has acted as a consultant for Boehringer Ingelheim, Corbus, CSL Behring, Eicos, Forbius, Chiara Stagnaro: None declared, Vanessa Smith Grant/research support from: The affiliated company received grants from Research Foundation - Flanders (FWO), Belgian Fund for Scientific Research in Rheumatic diseases (FWRO), Boehringer Ingelheim Pharma GmbH \& Co and Janssen-Cilag NV, Consultant of: Boehringer-Ingelheim Pharma GmbH \& Co, Speakers bureau: Actelion Pharmaceuticals Ltd, Boehringer-Ingelheim Pharma GmbH \& Co and UCB Biopharma Sprl, Richard Silver: None declared, Elena Schiopu: None declared, Valeria Riccieri: None declared, Frank Kramer Employee of: Bayer AG, Sindhu Johnson Grant/research support from: Boehringer Ingelheim, Corbus Pharmaceuticals, GlaxoSmithKline, Roche, Merck, Bayer, Consultant of: Boehringer Ingelheim, Ikaria, Osamu Ishikawa: None declared, Tomonori Ishii: None declared, Eric Hachlla: None declared, Ellen De Langhe Consultant of: member of advisory board for Boehringer, László Czirják Consultant of: Actelion, BI, Roche-Genentech, Lilly, Medac, Novartis, Pfizer, Bayer AG, Radim Bečvář Consultant of: Actelion, Roche, Tatsuya Atsumi Grant/research support from: Eli Lily Japan K.K., Alexion Pharmaceuticals, Inc., Bristol-Myers Squibb Co., AbbVie Inc., Daiichi Sankyo Co., Ltd., Pfizer Inc., Chugai Pharmaceutical Co., Ltd., Mitsubishi Tanabe Pharma Co., Astellas Pharma Inc., Consultant of:
Gilead Sciences, Inc., Eli Lilly Japan K.K., UCB Japan Co. Ltd., AbbVie Inc., Daiichi Sankyo Co., Ltd., Pfizer Inc., Chugai Pharmaceutical Co., Ltd., Speakers bureau: Eli Lilly Japan K.K., UCB Japan Co. Ltd., Bristol-Myers Squibb Co. AbbVie Inc., Eisai Co. Ltd., Otsuka Pharmaceutical Co., Ltd., Daiichi Sankyo Co., Ltd., Pfizer Inc., Chugai Pharmaceutical Co., Ltd., Mitsubishi Tanabe Pharma Co., Takeda Pharmaceutical Co., Ltd., Astellas Pharma Inc., Oliver Distler Grant/research support from: Grants/Research support from Actelion, Bayer, Boehringer Ingelheim, Competitive Drug Development International Ltd. and Mitsubishi Tanabe; he also holds the issued Patent on mir-29 for the treatment of systemic sclerosis (US8247389, EP2331143)., Consultant of: Consultancy fees from Actelion, Acceleron Pharma, AnaMar, Bayer, Baecon Discovery, Blade Therapeutics, Boehringer, CSL Behring, Catenion, ChemomAb, Curzion Pharmaceuticals, Ergonex, Galapagos NV, GSK, Glenmark Pharmaceuticals, Inventiva, Italfarmaco, iQvia, medac, Medscape, Mitsubishi Tanabe Pharma, MSD, Roche, Sanofi and UCB, Speakers bureau: Speaker fees from Actelion, Bayer, Boehringer Ingelheim, Medscape, Pfizer and Roche DOI: 10.1136/annrheumdis-2020-eular.3671

\section{OP0250 EFFICACY AND SAFETY OF ROMILKIMAB IN DIFFUSE CUTANEOUS SYSTEMIC SCLEROSIS (DCSSC): RANDOMIZED, DOUBLE-BLIND, PLACEBO- CONTROLLED, 24-WEEK, PROOF OF CONCEPT STUDY}

Y. Allanore ${ }^{1}$, P. Wung ${ }^{2}$, C. Soubrane ${ }^{3}$, C. Esperet $^{3}$, M. Frederic ${ }^{3}$, R. Bejuit ${ }^{3}$ A. Lahmar ${ }^{2}$, D. Khanna ${ }^{4}$, C. Denton ${ }^{5}{ }^{1}$ Cochin Hospital, Rheumatology, Paris, France; ${ }^{2}$ Sanofi R\&D, Bridgewater, United States of America; ${ }^{3}$ Sanofi $R \& D$, Chilly Mazarin, France; ${ }^{4}$ University of Michigan, Ann Arbor, United States of America; ${ }^{5}$ University College London, London, United Kingdom

Background: Systemic sclerosis (SSc) is a progressive, multi-organ disease with limited treatment options. Interleukin-4 (IL-4) and IL-13 have been implicated in the fibrotic pathway and pathogenesis of SSc and are promising targets. Romilkimab (RKB) is an engineered humanized bispecific Ig-G4 antibody that binds and neutralizes both IL-4/L-13. We report a Phase Ila randomized, double-blind, placebo-controlled trial (NCT02921971, Sanofi funded) employing RKB in SSc.

Objectives: To evaluate the efficacy and safety of RKB in dcSSc.

Methods: Patients with dcSSc duration $\leq 36$ months, mRSS 10-35, with or without immunosuppressive background therapy were randomized (1:1) to subcutaneous RKB $200 \mathrm{mg}$ or placebo (PBO) for 24 weeks and stratified on history of SSc-ILD. Primary endpoint was mean change in mRSS at Week 24 and FVC/DLCo and HAQ-DI were secondary endpoints. All analyses used a 1-sided p-value $<0.05$ as reaching statistical significance.

Results: Ninety-seven patients with similar baseline characteristics between arms, including use of background therapy (RKB $59.2 \%$ vs. PBO $52.1 \%$ ) were randomized. Six (12.2\%) and $4(8.3 \%)$ patients discontinued study treatment early in the PBO and RKB arms, respectively. Primary endpoint showed an absolute change in mRSS of $-2.45(0.85)$ and $-4.76(0.86)$ for PBO and RKB groups, respectively with a difference of -2.31 (1.21) favoring RKB $(p=0.029)$. Subgroup analysis based on background therapy showed a similar treatment effect with a PBO subtracted difference in mRSS of -2.69 (1.83) and -2.38 (1.59), suggesting an additive effect between background therapy and RKB. Secondary endpoints did not show a statistically significant difference between RKB vs. PBO arms, although there was numerically less decline in FVC with RKB with a PBO subtracted difference of $70 \mathrm{ml}(p=0.06)$. Exploratory endpoints suggested possible effect of RKB on overall pain, Raynaud's, digital ulcers, and EQ-5D-5L. Post-hoc analysis was undertaken to determine time to progression (first event defined as death, $\geq 10 \%$ relative decline in $\%$ predicted FVC, $\geq 15 \%$ relative decline in $\%$ predicted DLCO, $\geq 20 \%$ increase or +5 in mRSS, or other events: cardiac, SRC PAH development) and showed a benefit for RKB (HR: $0.47 \mathrm{p}=0.04$ ). Adverse events were balanced between the two groups (RKB $83.3 \%$ vs. PBO $83.7 \%$ ). There were 5 and 4 SAEs in the PBO and RKB arms, respectively. One death occurred in each arm (SRC - RKB, cardiomyopathy - PBO).

Conclusion: Patients with dcSSc who were treated with RKB showed a statistically significant reduction in mRSS compared to those receiving PBO. Secondary outcomes were not met, although RKB was associated with a smaller decline in FVC than PBO. Post-hoc analysis showed a possible reduction on time to progression with RKB. RKB was well tolerated with no major safety concerns.

\section{References: None.}

Disclosure of Interests: Yannick Allanore Grant/research support from: Yannick Allanore has received grants from Inventiva, Roche and Sanofi, Consultant of: Yannick Allanore has received fees from Actelion, Bayer, Boehringer Ingelheim, Bristol-Myers Squibb, Curzion, Inventiva, Roche, Sanofi, Peter Wung Shareholder of: I own Sanofi stock, Employee of: I work for Sanofi, Christina Soubrane Employee of: I work for Sanofi., Corinne Esperet Employee of: I work for Sanofi., MARRACHE Frederic Employee of: I work for Sanofi, 
Raphael Bejuit Employee of: I work for Sanofi., Amel Lahmar Employee of: I work for Sanofi., Dinesh Khanna Shareholder of: Eicos Sciences, Inc./Civi Biopharma, Inc., Grant/research support from: Dr Khanna was supported by NIH/ NIAMS K24AR063120, Consultant of: Acceleron, Actelion, Bayer, Boehringer Ingelheim, Bristol-Myers Squibb, Corbus Pharmaceuticals, Horizon Therapeutic, Galapagos, Roche/Genentech, GlaxoSmithKline, Mitsubishi Tanabe, Sanofi-Aventis/Genzyme, UCB, Christopher Denton Grant/research support from: GlaxoSmithKline, CSL Behring, and Inventiva, Consultant of: Medscape, Roche-Genentech, Actelion, GlaxoSmithKline, Sanofi Aventis, Inventiva, CSL Behring, Boehringer Ingelheim, Corbus Pharmaceuticals, Acceleron, Curzion and Bayer

DOI: 10.1136/annrheumdis-2020-eular.4830

\section{OP0251 THE EULAR SYSTEMIC SCLEROSIS IMPACT OF DISEASE (SCLEROID) SCORE - A NEW PATIENT- REPORTED OUTCOME MEASURE FOR PATIENTS WITH SYSTEMIC SCLEROSIS}

M. O. Becker ${ }^{1}$, R. Dobrota ${ }^{1}$, K. Fligelstone ${ }^{2}$, A. Roennow ${ }^{3}$, Y. Allanore ${ }^{4}$, P. Carreira ${ }^{5}$, L. Czirják ${ }^{6}$, C. Denton ${ }^{7}$, R. Hesselstrand ${ }^{8}$, G. Sandqvist ${ }^{8}$, O. Kowal-Bielecka ${ }^{9}$, C. Bruni ${ }^{10}$, M. Matucci Cerinic ${ }^{10}$, C. Mihai ${ }^{1}$, A. M. Gheorghiu ${ }^{11}$, U. Müller-Ladner ${ }^{12}$, J. Sexton ${ }^{13}$, T. Heiberg ${ }^{14}$, O. Distler ${ }^{1}$ ${ }^{1}$ Department of Rheumatology, University Hospital Zurich, Zurich, Switzerland; ${ }^{2}$ FESCA, London, United Kingdom; ${ }^{3}$ FESCA, Aalborg, Denmark; ${ }^{4}$ Department of Rheumatology, University Paris Descartes and Cochin Hospital, Paris, France; ${ }^{5}$ Department of Rheumatology, Hospital Universitario 12 de Octubre, Madrid, Spain; ${ }^{6}$ Department of Immunology and Rheumatology, Faculty of Medicine, University of Pécs, Pécs, Hungary; ${ }^{7}$ Centre for Rheumatology, Royal Free and University College London Medical School, Royal Free Campus, London, United Kingdom; ${ }^{8}$ Department of Rheumatology, Lund University, Lund, Sweden; ${ }^{9}$ Department of Rheumatology and Internal Medicine, Medical University of Bialystok, Bialystok, Poland; ${ }^{10}$ Department of Rheumatology, University of Florence, Florence, Italy; ${ }^{11}$ Department of Internal Medicine and Rheumatology, Cantacuzino Hospital, Carol Davila University of Medicine and Pharmacy, Bucharest, Romania; ${ }^{12}$ Department of Rheumatology and Clinical Immunology, Justus-Liebig University Giessen, Kerckhoff-Klinik Bad Nauheim, Bad Nauheim, Germany; ${ }^{13}$ Department of Rheumatology, Diakonhjemmet Hospital, Oslo, Norway; ${ }^{14}$ Department of Health and Social Sciences, Østfold University College, Oslo, Norway

Background: Patient reported outcome measures (PROM) are important for clinical practice and research. Given the unmet need for a comprehensive PROM for systemic sclerosis (SSc), the SclerolD questionnaire was developed by a joint team of patients with SSc and medical experts. This is intended as a brief, specific, patient-derived, disease impact score for research and clinical use in SSc. Objectives: Here, we present the validation and final version of the SclerolD.

Methods: This EULAR-endorsed project involves 9 European expert SSC centers. Patients fulfilling the ACR/EULAR 2013 criteria were prospectively included since 05/16 in a large observational cohort study. Patients completed the ScleroID and comparators SHAQ, EQ5D, SF36. They also weighted the 10 dimensions of the SclerolD by distributing 100 points according to the perceived impact on their health. The final score calculation is based on the ranking of the weights. The validation study included a reliability arm and a longitudinal arm, looking at sensitivity to change at follow-up.

Results: Of the 472 patients included at baseline, 109 patients also had a reliability visit and 113 patients a follow-up visit. $84.5 \%$ of patients were female, $29.8 \%$ had diffuse SSc, mean age was 54.6 years, and mean disease duration 9.5 years. The highest weights were assigned by the patients to Raynaud's phenomenon, fatigue, hand function and pain, confirming our previous results. The total SclerolD score showed good Spearman correlation coefficients with the comparators (SHAQ, 0.73; EQ5D -0.48; Patient's global assessment, VAS 0.77; HAQ-DI 0.62 ; SF36 physical score -0.62 ; each $p<0.001$ ). The internal consistency was good: Crohnbach's alpha 0.866, similar to SS-HAQ (0.88) and higher than EQ5D (0.77). The SclerolD had a very good reliability: intra-class correlation coefficient 0.839 (ranging 0.608 to 0.788 for the individual items), superior to all comparators. Twenty of 113 patients reported a change in their disease status at follow up. Sensitivity to change: the standardized response mean was 0.34 for the total SclerolD score and highest for lower $\mathrm{Gl}(0.633)$ and life choices domains (0.521), superior to all other PROM. Figure 1 shows the final SclerolD.

\section{The EULAR Scleroderma Impact of Disease Score} (SclerolD)

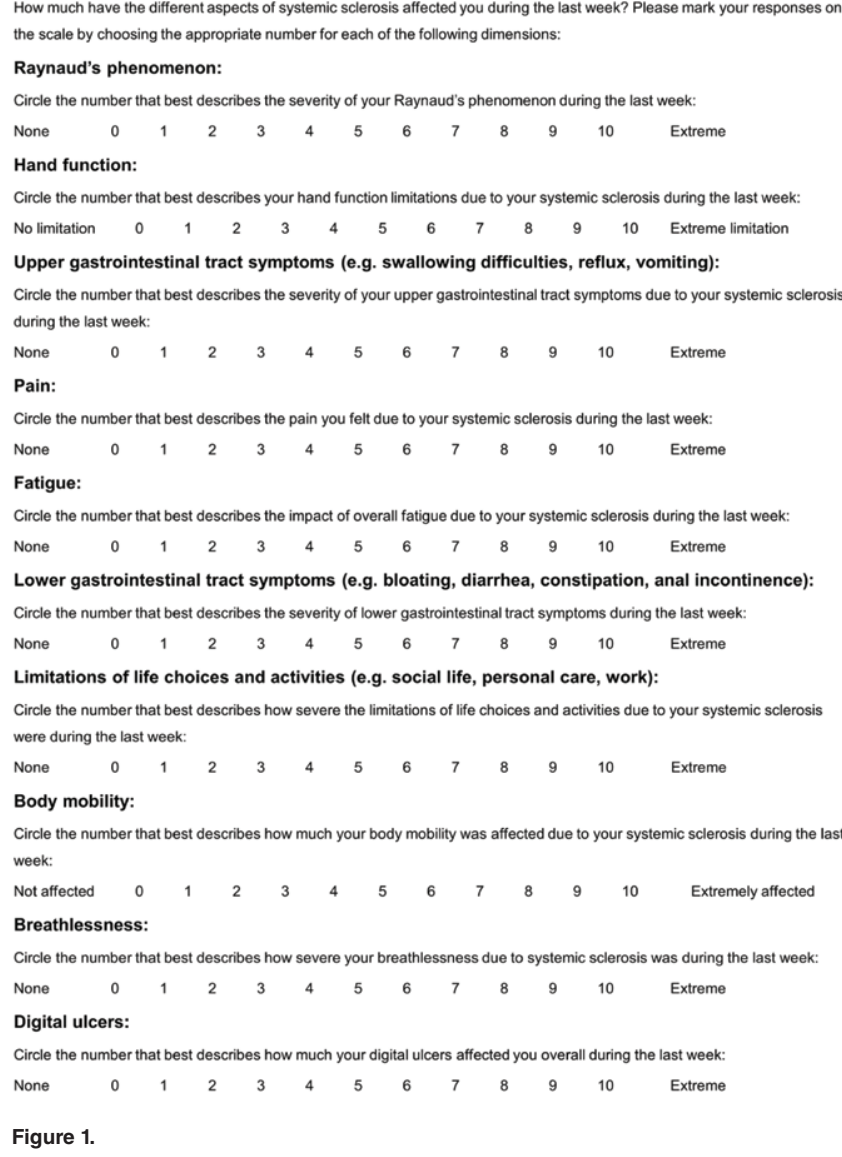

Conclusion: The EULAR SclerolD is a novel PROM designed for use in clinical practice and clinical trials to reflect the disease impact of SSc, showing good performance in the validation study. Importantly, Raynaud syndrome, impaired hand function, pain and fatigue were the main patient reported drivers of disease impact.

Disclosure of Interests: Mike O. Becker: None declared, Rucsandra Dobrota: None declared, Kim Fligelstone: None declared, Annelise Roennow: None declared, Yannick Allanore Grant/research support from: BMS Inventiva, Roche, Sanofi, Consultant of: Actelion, Bayer AG, BMS, BI, Patricia Carreira Grant/research support from: Actelion, Roche, MSD, Consultan of: GlaxoSmithKline, VivaCell Biotechnology, Emerald Health Pharmaceuticals, Boehringer Ingelheim, Roche, Speakers bureau: Actelion, GlaxoSmithKline, Roche, László Czirják Consultant of: Actelion, BI, Roche-Genentech, Lilly, Medac, Novartis, Pfizer, Bayer AG, Christopher Denton Grant/research support from: GlaxoSmithKline, CSL Behring, and Inventiva, Consultant of: Medscape, Roche-Genentech, Actelion, GlaxoSmithKline, Sanofi Aventis, Inventiva, CSL Behring, Boehringer Ingelheim, Corbus Pharmaceuticals Acceleron, Curzion and Bayer, Roger Hesselstrand: None declared, Gunnel Sandqvist: None declared, Otylia Kowal-Bielecka Consultant of: Bayer Boehringer Ingelheim, Inventiva, MSD, Medac, Novartis, Roche and Sandoz, Speakers bureau: Bayer, Boehringer Ingelheim, Inventiva, MSD Medac, Novartis, Roche and Sandoz, Cosimo Bruni Speakers bureau: Actelion, Eli Lilly, Marco Matucci Cerinic: None declared, Carina Mihai: None declared, Ana Maria Gheorghiu: None declared, Ulf Müller-Ladner Speakers bureau: Biogen, Joe Sexton: None declared, Turid Heiberg: None declared Oliver Distler Grant/research support from: Grants/Research support from Actelion, Bayer, Boehringer Ingelheim, Competitive Drug Development International Ltd. and Mitsubishi Tanabe; he also holds the issued Patent on mir-29 for the treatment of systemic sclerosis (US8247389, EP2331143). Consultant of: Consultancy fees from Actelion, Acceleron Pharma, AnaMar Bayer, Baecon Discovery, Blade Therapeutics, Boehringer, CSL Behring, Catenion, ChemomAb, Curzion Pharmaceuticals, Ergonex, Galapagos NV GSK, Glenmark Pharmaceuticals, Inventiva, Italfarmaco, iQvia, medac, Medscape, Mitsubishi Tanabe Pharma, MSD, Roche, Sanofi and UCB, 